FACULTY OF ECONOMICS AND APPLIED ECONOMIC SCIENCES

CENTER FOR ECONOMIC STUDIES

ENERGY, TRANSPORT \& ENVIRONMENT

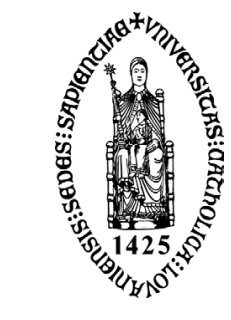

KATHOLIEKE UNIVERSITEIT

LEUVEN

WORKING PAPER SERIES

$n^{\circ}$ 2003-14

\title{
Regulating transmission in a spatial oligopoly: a numerical illustration for Belgium
}

\author{
G. Pepermans (K.U.Leuven) \\ B. Willems (K.U.Leuven)
}

December 2003

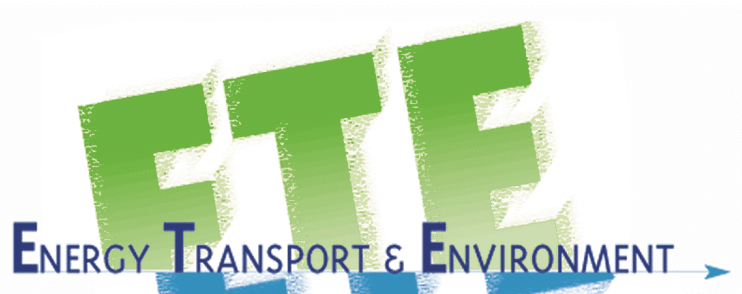

secretariat:

Isabelle Benoit

KULeuven-CES

Naamsestraat 69, B-3000 Leuven (Belgium)

tel: $\quad+32(0) 1632.66 .33$

fax: $\quad+32(0) 1632.69 .10$

e-mail: Isabelle.Benoit@econ.kuleuven.ac.be http://www.kuleuven.be/ete 


\title{
Regulating transmission in a spatial oligopoly: a numerical illustration for Belgium
}

\author{
Guido Pepermans and Bert Willems \\ http://www.econ.kuleuven.ac.be/ete/
}

December 11, 2003

\begin{abstract}
This paper introduces strategic behavior of the electricity network operator in a congested network with imperfect competition for generation. It models a two stage Stackelberg game. First, the network operator sets transmission prices, then generators set output and sales. Several scenarios for the generation market structure and the behavior of the network operator are compared numerically. The calibration of the numerical model is based on data of the Belgian electricity market.
\end{abstract}

\section{Introduction}

This paper models how a network operator would set transmission tariffs under a number of assumptions. We illustrate, with a numerical model that captures the major technical features of the Belgian electricity system, how transmission prices are a function (1) of the behavior of the network operator, (2) of the level of competition in generation, and (3) of the availability of transmission capacity.

In contrast with most of the literature, the paper explicitly models the strategic behavior of the network operator. For expositional purposes, we present this behavior by considering two stages.

In the first stage, the network operator maximizes his or her objective function by setting transmission tariffs, while taking into account the subsequent actions of generators and consumers. Two alternative objective functions are considered for the network operator: either he maximizes profit, or he maximizes welfare subject to a budget constraint. These objective functions can be seen as two extreme cases, as, in practice, profit will be maximized subject to some form of regulation constraint.

In the second stage, generators take transmission prices as given, while deciding about the level of production in each of their generation plants and about the level of sales to different consumers. The latter are assumed to be price takers. Three alternative scenarios are developed for the generation market. The first scenario is the benchmark and assumes 
perfect competition in generation. In the second scenario, generation is a monopoly market. As the Belgian electricity market is currently highly concentrated (the largest generator has $83 \%$ of the production capacity), this scenario could be considered as the current situation. The third scenario considers three Cournot players in generation. This can be interpreted as a market where some of the monopolist's production capacity is virtually auctioned, a mechanism that will shortly be implemented in Belgium.

As stated before, the model is illustrated with some numerical simulations. The model that is used for this, is inspired by the Belgian electricity system in terms of the major technical characteristics of both generation and transmission, and in terms of the demand for electricity. The grid and generation characteristics will be described in more detail in section 4 .

The structure of the paper is as follows: the next section reviews some relevant and related literature and the sections 3 and 4 describe the structure of the model and the data, respectively. Section 5 discusses simulation results and, finally, section 6 presents conclusions and some extensions for future research.

\section{Survey of the literature}

This section starts with a description of models of imperfect competition in electricity generation without transmission constraints, and continues with a discussion of some Cournot models in which transmission constraints are present. The last part looks at the strategic behavior of the network operator.

\subsection{Imperfect competition in electricity markets}

Due to the non storability of electricity and its highly variable demand, electricity systems tend to feature a mix of base load plants and peak load plants. Peak load plants are typically characterized by high marginal production costs and low investment costs, while base load plants typically have low marginal costs and high investment costs. Peak load plants are only used in periods of high demand, base load plants are used at all times. Peak load power and base load power could therefore be considered as two different goods. To model imperfect competition in such a multi-good market, two types of equilibrium have been developed: the multi unit auction and the supply function equilibrium.

Multi-unit auction In the multi-unit auction, generators bid a price for each plant at which they are willing to supply given capacities ${ }^{1}$. The equilibrium price, determined as the price that clears the market, is applied to all inframarginal units ${ }^{2}$. In this setting, bidders, offering more than one unit of capacity, have an incentive to increase their bids for those plants that are likely to be marginal. Wolfram (1998) finds empirical evidence that,

\footnotetext{
${ }^{1}$ See for instance the models of Von der Fehr and Harbord (1993).

${ }^{2}$ Other types of auctions can also be considered.
} 
in the England \& Wales market, large players effectively try to use their market power in this way.

Multi-unit auctions are particulary hard to model, and do not always have a Nash equilibrium.

Supply Function Equilibrium The supply function equilibrium concept is based on Klemperer and Meyer (1989). Generators choose a continuous and differentiable supply function, which, for each price, specifies the quantity they are willing to generate. Again, the electricity price is established as the market clearing price. Klemperer and Meyer show that an infinite number of Nash equilibria exist when electricity demand is known with certainty. The reason is that only one point on the supply function is required to determine the market clearing price, the remainder of the supply function can be chosen more or less free.

However, if electricity demand is uncertain when generators decide about their supply function, then the latter function has to be appropriate for several situations, and the number of equilibria is reduced ${ }^{3}$. Klemperer and Meyer even show that, under certain conditions, the differentiable supply function equilibrium becomes unique.

Green and Newbery (1992) apply the Klemperer and Meyer model to the two largest generators in the English market ${ }^{4}$. By adding an output constraint for each generator, they can further reduce the set of equilibria. Furthermore, Green and Newbery assume that generators will coordinate on the equilibrium that maximizes total profit. Their model predicts that, in the absence of a threat of entry, the two generators are able to sustain a non-collusive equilibrium in which prices are well above operating costs.

One of the major drawbacks of the two types of models discussed above is that the spatial structure of the electricity market, and therefore the impact of transmission constraints, is omitted. Neither of these two approaches is applicable (yet) in a market with transmission constraints. Most researchers therefore opt for some kind of Cournot market, while dropping some of the multi-good aspects of the actual market. In an empirical study, Wolak and Patrick (2001) suggest that Cournot competition is an appropriate representation of the electricity generation market. They argue that the market power of dominant generators is manifested through those generators declaring certain plants unavailable in certain periods ${ }^{5}$.

\subsection{Cournot in generation - Price taking in transmission}

Even Cournot models become quite cumbersome when simulations are made for larger networks with transmission constraints. This is the case because generators realize that,

\footnotetext{
${ }^{3}$ Klemperer and Meyer consider horizontal shifts in demand.

${ }^{4}$ Other studies using this model are Bolle (1992), Newbery (1998), Green (1996) and Rudkevich, Duckworth and Rosen (1998).

${ }^{5}$ Other studies using Cournot competition are Oren (1997) Stoft (1997), Borenstein, Bushnell and Stoft (1998), Borenstein, Bushnell and Knittel (1999), Borenstein and Bushnell (1999), Hogan (1997), Cardell, Hitt and Hogan (1997).
} 
with scarce transmission capacity, transmission prices can be influenced, and congestion can be created. Cournot-Nash equilibria are then no longer guaranteed to exist, and rationing rules need to be added to the model. Therefore, this paper assumes that generators behave à la Cournot in the energy market (buying and selling of electricity), but are price takers in the transmission market. This approach is inspired by the model of Smeers and Wei (1997, 1999).

Different assumptions can be made with respect to price setting in the transmission market, for example congestion pricing (Smeers and Wei, 1997), regulated pricing (Smeers and Wei, 1999), and strategic price setting (this paper). A short discussion follows.

Congestion pricing Smeers and Wei (1997) assume that the network operator sets prices for using the network on the basis of congestion charges $(C C)$. As long as a line is not used at full capacity, the transmission tariff equals zero. If the line becomes congested, the transmission tariff is increased until demand for transmission equals supply. This can be illustrated for a network with one line of capacity $k$. With $x$ the demand on the line, and $\tau$ the transmission tariff, we have:

$$
\begin{aligned}
\tau^{C C}(x) & =0 \text { IF }|x|<k \\
& >0 \text { IF } x=k \\
& <0 \text { IF } x=-k
\end{aligned}
$$

Congestion pricing can be interpreted as the result of assuming that the network operator behaves perfectly competitive. Thus, the network operator acts as a price taker in the transmission market and appears to be unaware of his market power in that market. Congestion charges can be implemented when the network operator is forced to sell all transmission capacity in an auction, is not allowed to withhold capacity from the market, and is not allowed to set a minimal reservation price for the transmission rights.

Regulated prices Wei and Smeers (1999) study regulated transmission prices. Here, the transmission charge is the sum of two parts: a congestion charge $\tau^{C C}$, and a regulated charge $\tau^{R 6}$ :

$$
\tau(x)=\tau^{C C}(x)+\tau^{R}(x)
$$

The term $\tau^{R}(x)$ is set according to a regulatory rule which depends on the use of the line. They study two types of regulatory rules: marginal cost pricing and average cost pricing. The average cost rule sets the regulated charge for a transmission line equal to the average cost of building a new transmission line. With the marginal cost rule, the regulated charges are set according to the marginal cost of building transmission lines.

The congestion charge $\tau^{C C}(x)$ is required to clear the market when the demand for transmission is in excess of available capacity at a transmission price equal to the regulated

\footnotetext{
${ }^{6}$ Wei and Smeers (1999) give a different interpretation to the congestion charges than we do here. They look for a Generalized Nash Equilibrium where transmission constraints are internalized. In that case, congestion charges are internal multipliers. See also the previous chapter, and the introduction.
} 
charge $\tau^{R}(x)$. Wei and Smeers assume that congestion charges are not used to refund the network operator for building new transmission capacity ${ }^{7}$.

The Smeers and Wei model and the model in this paper are different because the first model does not include Kirchhoff's laws. On the other hand, Smeers and Wei also model investment in new transmission capacity, something which is not included in this paper's model.

Prices chosen by the network operator In this paper, the network operator is no longer assumed to behave as a passive player, but rather as a Stackelberg leader in a two-stage game. In stage one, he maximizes his objective function by setting transmission prices, while taking into account the effect of its pricing decision on the strategic behavior of the players in the generation market. Transmission demand is thus assumed to be price responsive. In the second stage, generators behave à la Cournot.

Two alternative and extreme assumptions with respect to the network operator's objective function are discussed in the paper: profit maximization and welfare maximization subject to a budget constraint. Network operation is commonly accepted to be a natural monopoly, and, therefore, without regulation the network operator would simply maximize profit (Case 1). The second alternative assumption is that regulation is perfect, and that the network operator maximizes welfare subject to a budget constraint (nonnegative profit).

\section{The model}

Define the sets $F$ and $G$ as the sets of generation firms and generation plants. Let $G_{f}$ be the set of generation units owned by generation firm $f \in F$. With $I$ being the set of network nodes, $G_{i}$ denotes the generation plants at node $i \in I$, and $G_{f i}$ the generation plants at node $i$ owned by firm $f$. The network contains a number of nodes $i \in I$. Furthermore, let $A$ be the set of transmission lines in the network, with $a(i, j) \in A$ the line connecting the nodes $i$ and $j$.

For notational simplicity, the model will be further described as if it concerned a one period model, i.e. a model that does not distinguish between peak and off-peak periods. However, the numerical simulations discussed in section 5 also cover a case that differentiates between peak and off-peak demand in a 4-period model.

The model distinguishes three types of players: consumers, generation firms and the network operator.

Consumers are price takers. At node $i$, they consume $s_{i}$ units of electricity. Their inverse demand for electricity, denoted as $p_{i}\left(s_{i}\right)$, is downward sloping and concave. Consumer prices include compensation for both the generation and the transmission of electricity.

Generation firm $f \in F$ maximizes profits, while acting as a price taker in transmission. At node $i$, it owns the generation plants $g \in G_{f i}$.

\footnotetext{
${ }^{7}$ It has often been argued that congestion payments should not go to the network operator as this could give the wrong incentives.
} 
Electricity generation in plant $g$ is $q_{g}$ and the generation cost is $C_{g}\left(q_{g}\right)$. Total generation costs are convex, with fixed generation costs normalized to zero. The generation capacity of plant $g$ is labelled $\bar{q}_{g}$. Output should be nonnegative, and cannot exceed available generation capacity. Therefore, we have

$$
0 \leq q_{g} \leq \bar{q}_{g}
$$

The network operator or transmission company either maximizes profit or social welfare, depending on the assumptions taken later on. The transmission company sets a nodal transmission charge $\tau_{i}^{c}$ for consumers and $\tau_{i}^{g}$ for generators. This is the per unit payment generators have to make for injecting power, and that consumers have to pay to take power from the grid. These charges can be different. For instance, a generator who generates electricity in node $i$ and sell electricity in node $j$ will pay $\tau_{i}^{g}+\tau_{j}^{c}$. Only the sum of the consumer and generation transmission charge is important, and therefore one of the charges can be set equal to zero without loss of generality.

As explained before, the model has two stages. In the first stage, the transmission operator sets transmission prices. In the second stage, generation firms play a Cournot game in which transmission prices and their competitor's quantities are assumed as given. The next subsection describes the second stage of the game.

\subsection{The second stage}

Each firm $f$ observes the transmission charges $\tau_{i}^{p}$ and $\tau_{i}^{c}$ as set by the network operator and plays a Cournot game. A firm $f$ collects revenue by selling $s_{f i}$ units of electricity at node $i$ at the per unit price $p_{i}$. Firms also set the production level $q_{g}\left(g \in G_{f}\right)$ at each of their plants Their competitor's sales in node $i$, denoted by $\tilde{s}_{-f i}$, are taken as given. Apart from generation costs, firms also pay a transmission cost $\tau_{i}^{p}$ for injecting electricity to the network at node $i$, and $\tau_{i}^{c}$ for the delivery of electricity to node $i$. This results in the following profit function for generation firm $f$,

$$
\Pi_{f}^{G e n}=\sum_{i \in I}\left(p_{i}-\tau_{i}^{c}\right) \cdot s_{f i}-\sum_{i \in I} \sum_{g \in G_{f_{i}}}\left[C_{g}\left(q_{g}\right)+\tau_{i}^{p} q_{g}\right]
$$

The nodal price $p_{i}$ that is received by generator $f$ depends on the total sales in that node, i.e.

$$
\begin{aligned}
p_{i} & =p_{i}\left(s_{i}\right) \\
s_{i} & =s_{f i}+\tilde{s}_{-f i}
\end{aligned}
$$

where a tilde indicates that the variable is considered as given. In equation 3 , the first term reflects revenues from electricity sales net of transmission charges paid at the consumption nodes. The second term reflects generation costs and transmission charges to put the electricity on the network. Summarizing, we have the following maximization problem for 
a generator:

$$
\max _{s_{f i}, q_{g}\left(g \in G_{f}\right)} \Pi_{f}^{G e n}=\sum_{i \in I}\left(p_{i}\left(s_{i}\right)-\tau_{i}^{c}\right) \cdot s_{f i}-\sum_{i \in I} \sum_{g \in G_{f_{i}}}\left[C_{g}\left(q_{g}\right)+\tau_{i}^{p} q_{g}\right]
$$

Subject to:

$$
\begin{gathered}
0 \leq q_{g} \leq \bar{q}_{g} \quad\left(\underline{\mu}_{g}, \bar{\mu}_{g}\right) \quad \forall g \in G_{f} \\
\sum_{i \in I} s_{f i}=\sum_{g \in G_{f}} q_{g} \quad\left(\lambda_{f}^{p}\right) \\
s_{i}=s_{f i}+\tilde{s}_{-f i} \quad \forall i \in I
\end{gathered}
$$

As noted before, the first constraint reflects generation capacity constraints. The second constraint represents the energy balance at the firm level, i.e. total output should equal total sales. The last constraint represents demand. This constraint has no multiplier as it is substituted into the objective function and the other constraints before derivatives are taken.

The following first order conditions are then derived:

$$
\begin{gathered}
\frac{\partial C_{g}\left(q_{g}\right)}{\partial q_{g}}+\tau_{i}^{p}+\underline{\mu}_{g}-\bar{\mu}_{g}=\lambda_{f}^{p} \quad \forall g \in G_{f i}, \forall i \in I \\
p_{i}+\frac{\partial p_{i}\left(s_{i}\right)}{\partial s_{i}} s_{f i}-\tau_{i}^{c}=\lambda_{f}^{p} \quad \forall i \in I
\end{gathered}
$$

These are the standard first-order conditions for profit maximization, i.e. as long as generation constraints are not binding, marginal revenue equals marginal cost in all market segments. The Lagrange multiplier of the energy balance constraint $\lambda_{f}^{p}$, is the value of energy in the network for generation firm $f$. This value is different for every firm.

Cost minimization requires that each firm equalizes the sum of the marginal cost and the generation charge at all generation plants. Profit maximization requires that marginal revenues net of consumption charges are equalized.

Each firm's reaction function with respect to the sales $s_{-f i}$ and the transmission charges, $\tau_{i}^{c}$ and $\tau_{i}^{g}$ can be derived from the equations 4,5 and 6 .

In the remainder of this paper, we assume that the generation constraints are not binding $\left(\underline{\mu}_{g}=\bar{\mu}_{g}=0\right)$. Without this assumption, the network operator's problem becomes intractable. The firms will thus not choose corner solutions. This is the case when (1) the marginal costs are zero for zero output

$$
\lim _{q_{g} \rightarrow 0} \frac{\partial C_{g}\left(q_{g}=0\right)}{\partial q_{g}}=0
$$

and (2) sufficiently large at full output

$$
\lim _{q_{g} \rightarrow \bar{q}_{g}} \frac{\partial C_{g}\left(q_{g}\right)}{\partial q_{g}}=\infty
$$


Electricity transmission The model should allow simulating of the effects of structural and regulatory changes in the electricity sector. Therefore, the technical features of the electricity system, especially at the level of electricity transport, should also be captured by the model. Electricity transport is subject to physical constraints. These constraints have an impact on the power flow through the network and therefore potentially also on the pricing of transmission services. In this paper we concentrate on active power and we adopt a simplified DC flow model without losses. ${ }^{8}$

Each line in the network is characterized by a transmission capacity and its admittance. For example, the line $a(i, j)$ connecting the nodes $i$ and $j$ has a capacity $\bar{Q}_{a(i, j)}$ and an inductance $Y_{a(i, j)}{ }^{9}$. Denoting the flow over the line $a$ as $Q_{a}$, we must have

$$
Q_{a} \leq \bar{Q}_{a} \quad \forall a \in A
$$

Transmission must be smaller than the available transmission capacity. This is also called the thermal constraint of line $a$, because the line's temperature increases too much if the line carries larger flows.

The flow over a line $a(i, j)$ is proportional to the difference of the phase angles in the begin and end point, i.e.

$$
Q_{a(i, j)}=Y_{a(i, j)}\left(\delta_{i}-\delta_{j}\right) \quad \forall a(i, j) \in A
$$

As there is one degree of freedom in choosing phase angles, one phase angle, located at the so-called swing node, is set equal to zero.

$$
\delta_{i}=0, i=\text { swing node }
$$

The physical properties of the network can be summarized by a set of nodal equations, and a set of line equations. In each node, the flows entering and leaving the node should balance, i.e.

$$
q_{i}-s_{i}=\sum_{j \in I} Q_{a(i, j)} \quad \forall i \in I
$$

with $s_{i}, q_{i}$ the total consumption and generation in node $i$ :

$$
\begin{aligned}
& s_{i}=\sum_{f \in F} s_{f i} \quad \forall i \in I \\
& q_{i}=\sum_{g \in G_{i}} q_{g} \quad \forall i \in I
\end{aligned}
$$

The left hand side of 10 is the surplus of local production in node $i$ (=production consumption in node $i$ ). The right hand side is the sum of the flows leaving node $i$.

Equations 7 - 9 describe the transmission possibilities of the network, i.e. they define the production feasibility set of the network operator.

\footnotetext{
${ }^{8}$ Such a model assumes that line resistance is small relative to reactance, that voltage magnitudes are the same at all nodes, and that voltage angles between nodes at opposite ends of a transmission line are small. Engineers often use the linearized model of the network for long term planning.

The alternative, AC-power flow, was used in a previous version of the program, but did not give fundamentally different results.

${ }^{9}$ The shorthand $a$ will be used to indicate a line $a(i, j)$ if this can be done without creating confusion.
} 
Security of supply The network operator also needs to secure the supply of electricity. A minimal requirement for this is that, if unexpectedly a line goes out of service the remaining lines should still be able to transport all supplied electricity. This is the socalled $n-1$ rule, i.e. if a line $\alpha \in A$ breaks down, the set of the remaining lines $A /\{\alpha\}$ should be able to transport the power over the network. After a contingency, the flows redistribute themselves over the network, and these new flows should still be feasible given the thermal constrains of the networks. Clearly, taking into account the $n-1$ rule has an impact on the constraints $7,8,11$ and 12 . These equations become

$$
\begin{gathered}
q_{i}-s_{i}=\sum_{a(i, j) \in A \backslash\{\alpha\}} Q_{a(i, j)}^{\alpha} \quad \forall i \in I \\
Q_{a(i, j)}^{\alpha}=Y_{a(i, j)}\left(\delta_{i}^{\alpha}-\delta_{j}^{\alpha}\right) \quad \forall \alpha \in A, \forall a \in A \backslash\{\alpha\} \\
\delta_{i}^{\alpha}=0, \quad i=\text { swing node, } \forall \alpha \in A \\
Q_{a}^{\alpha} \leq \bar{Q}_{a} \quad \forall a \in A \backslash\{\alpha\}
\end{gathered}
$$

The variable $Q_{a}^{\alpha}$ denotes the flow on line $a$ when line $\alpha$ fails. Each of these constraints must be satisfied for each potential line breakdown. The equations 7 to 16 form the network equations of the model.

\subsection{The first stage}

The network operator is either a profit-maximizing firm or a welfare maximizing firm, subject to a budget constraint. The objective is maximized by setting consumption and generation transmission charges $\left(\tau_{i}^{c}\right.$ and $\left.\tau_{i}^{p}\right)$, which can be differentiated over the nodes. It is assumed that the cost of providing transmission services is separable into operating costs and capacity costs. In the present model, operating costs and network losses are neglected. Therefore, only the capacity costs $B$ remain.

The profit of the network operator is then equal to:

$$
\Pi^{t r}=\sum_{i \in I}\left(\tau_{i}^{c} s_{i}+\tau_{i}^{p} q_{i}\right)-B
$$

The first term between brackets is the revenue of selling transmission services to consumers at node $i$. The second term is the revenue of selling transmission to the generators. The last term represents capacity costs. By assumption, capacity costs are fixed.

Profit maximization With profit maximization, the network operator maximizes profits $\Pi^{\text {tr }}$ subject to

the energy balance at the firm level,

$$
\sum_{i \in I} s_{f i}=\sum_{g \in G_{f}} q_{g} \quad \forall f \in F \backslash\left\{f_{1}\right\}
$$


the Cournot behavior (Sales - Production)

$$
\begin{aligned}
p_{i}\left(s_{i}\right)+\frac{\partial p_{i}\left(s_{i}\right)}{\partial s_{i}} s_{f i}-\tau_{i}^{c} & =\lambda_{f}^{p} \quad \forall i \in I, \forall f \in F \\
\frac{\partial C_{g}\left(q_{g}\right)}{\partial q_{g}}+\tau_{i}^{p} & =\lambda_{f}^{p} \quad \forall i \in I, \forall f \in F, \forall g \in G_{f i}
\end{aligned}
$$

and the ten network equations 7 - 16 :

$$
\begin{gathered}
q_{i}-s_{i}=\sum_{j \in I} Q_{a(i, j)} \quad \forall i \in I \\
Q_{a} \leq \bar{Q}_{a} \quad\left(\gamma_{t}^{t r}\right) \quad \forall a \in A \\
Q_{a(i, j)}=Y_{a(i, j)}\left(\delta_{i}-\delta_{j}\right) \quad \forall a \in A \\
\delta_{i}=0, \quad i=\text { swing node } \\
s_{i}=\sum_{f \in F} s_{f i} \quad \forall i \in I \\
q_{i}=\sum_{g \in G_{i}} q_{g} \quad \forall i \in I \\
\tau_{i}^{c}=0 \quad i=\operatorname{swing} \text { node } \\
q_{i}-s_{i}=\sum_{a(i, j) \in A \backslash\{\alpha\}} Q_{a}^{\alpha} \quad \forall \alpha \in A, \forall i \in I \\
Q_{a(i, j)}^{\alpha}=Y_{a(i, j)}\left(\delta_{i}^{\alpha}-\delta_{j}^{\alpha}\right) \quad \forall \alpha \in A, \forall a \in A \backslash\{\alpha\} \\
\delta_{i}^{\alpha}=0, \quad i=\operatorname{swing} \text { node, } \forall \alpha \in A \\
Q_{a}^{\alpha} \leq \bar{Q}_{a} \quad \forall \alpha \in A, \forall a \in A \backslash\{\alpha\}
\end{gathered}
$$

Note that the set of network equations implies global energy balance, i.e. total production is equal to total consumption. Therefore one of the energy balances of the generators can be dropped from the optimization problem.

The two constraints that describe the Cournot behavior of the generator define a nonconvex constraint. Therefore the problem does not need to have a unique local optimum.

Welfare maximization Under welfare maximization the network operator maximizes

$$
W=\sum_{i \in I} \int_{0}^{s_{i}} p_{i}(t) d t-\sum_{g \in G} C_{g}\left(q_{g}\right)
$$

subject to the network constraints 7 - 16, the Cournot behavior of the generators (18 20) and the budget constraint:

$$
\sum_{i \in I}\left(\tau_{i}^{c} s_{i}+\tau_{i}^{p} q_{i}\right)-B=\Pi^{t r} \geq 0
$$

This latter constraint is added in order to avoid that the network operator goes bankrupt. 


\section{Data and calibration}

Before continuing with the simulations, we discuss the data that have been used as an input for the model. Also, the calibration procedure will be described. The choice of the technical features of the transmission grid and of the available generation plants is inspired by the Belgian electricity system. This is, however, not the case for the regulatory framework. Here, we make two extreme assumptions, i.e. perfect regulation versus no regulation.

\subsection{The Network}

Figure 1 shows the network that has been used. It consists of 55 nodes and 92 lines and includes all the Belgian $380 \mathrm{kV}$ and $220 \mathrm{kV}$ transmission lines, but also some $380 \mathrm{kV}$ lines in The Netherlands and France because they are important for the flows inside the Belgian network. The full lines on the graph are $380 \mathrm{kV}$ lines, the dotted lines are $220 \mathrm{kV}$ lines. The line between Gouy and Avelgem represents several lines of the $110 \mathrm{kV}$ network that connect both nodes. ${ }^{10}$

The data of the lines are given in the Table 1. It gives, for each line, information on origin and destination, voltage level, admittance, thermal capacity, and whether the line is used in the contingency analysis.

Some of the columns require more explanation. The admittance of each line is normalized on the basis of the reference voltage level of the lines $\left(V^{r e f}=380,220\right.$ or $\left.110 \mathrm{kV}\right)$ and the reference power level $\left(S^{r e f}=1 M W\right)$. The normalized admittance is equal to

$$
Y_{a}=\frac{\left(V_{a}^{r e f}\right)^{2}}{S^{r e f} \sqrt{X_{a}^{2}+R_{a}^{2}}}
$$

with $X_{a}[\mathrm{Ohm}]$ and $R_{a}[\mathrm{Ohm}]$ the resistance and the reactance of the lines.

The last column of Table 1 indicates whether the line is checked for the $n-1$ security constraint. For a line indicated with $\mathrm{Y}(=$ Yes) we make sure that when it breaks down that the remaining (92-1) lines can transport the electricity. The $n-1$ rule is checked for all Belgian $380 \mathrm{kV}$ lines, except for some loose ends. Line 34 (Drogenbos - Mekingen) is such a loose end, i.e. Drogenbos can only be supplied via the line from Mekingen. Using the $n-1$ rule for this line makes no sense when we do not include lower voltage levels.

The $n-1$ rule is not imposed for the interconnections with France and The Netherlands and for the lines within these countries, because sufficient or adequate information is lacking.

\footnotetext{
${ }^{10}$ Network data was kindly provided by Peter Van Roy and Konrad Purchala of the Department of Electrical Engineering.
} 


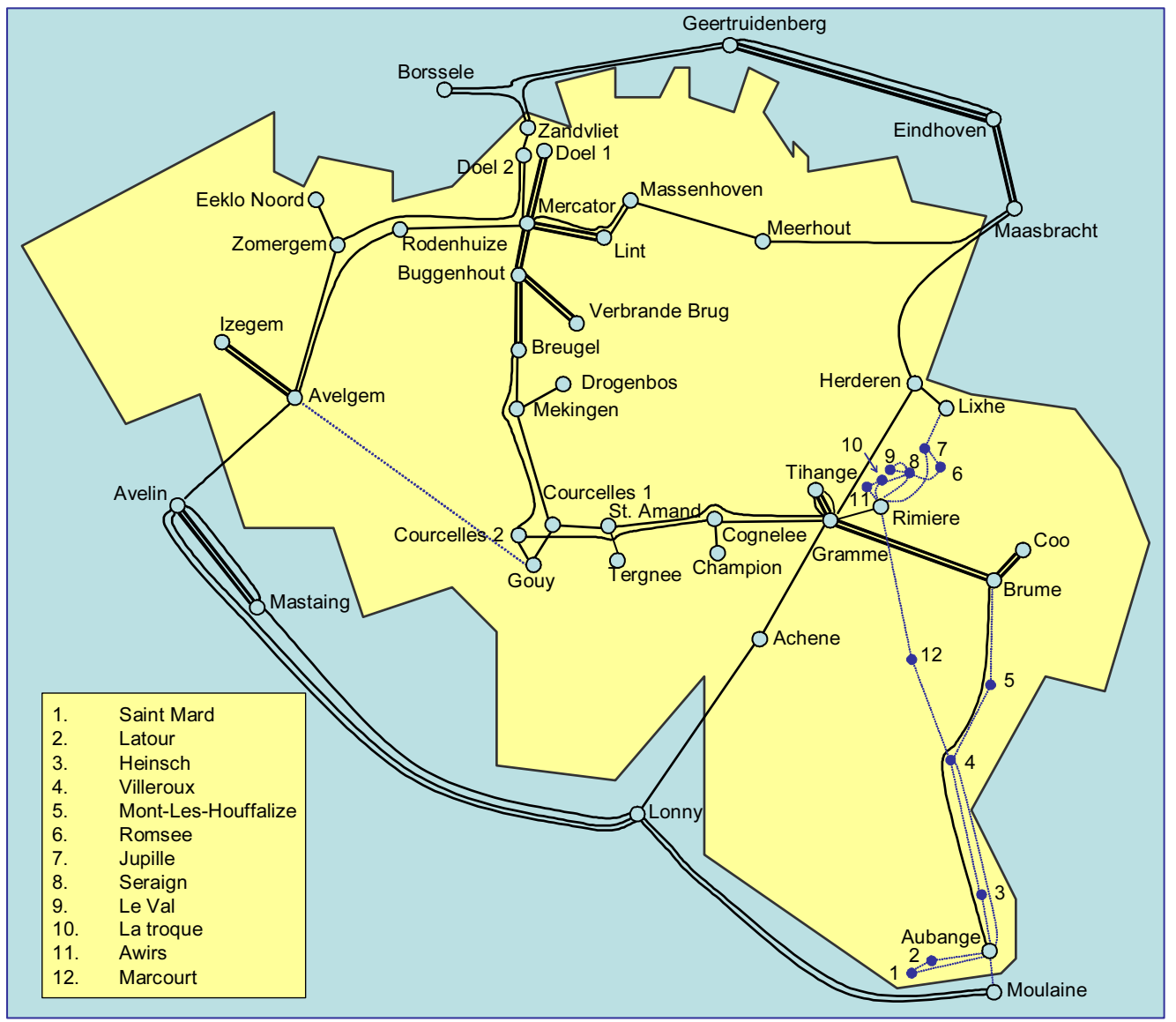

Figure 1: The Belgian high voltage network, situation in 2002. 


\begin{tabular}{|c|c|c|c|c|c|}
\hline \# line FROM & TO & $\begin{array}{r}V \\
(k V)\end{array}$ & $\begin{array}{r}Y \\
\text { (p.u.) }\end{array}$ & $\begin{array}{c}\left.\bar{Q}_{i, j}\right) \\
\text { (MW) }\end{array}$ & $\begin{array}{c}\mathrm{N}-1 \\
\text { (Yes) }\end{array}$ \\
\hline 1 Achene & Gramme & 380 & 13165 & 1316 & $\bar{Y}$ \\
\hline 2 Achene & Lonny & 380 & 8071 & 1179 & \\
\hline 3 Aubange & Brume & 380 & 5094 & 790 & Y \\
\hline 4 Avelgem & Avelin (FR) & 380 & 11321 & 1179 & Y \\
\hline 5 Avelgem & Izegem & 380 & 21310 & 1420 & Y \\
\hline 6 Avelgem & Izegem & 380 & 21310 & 1420 & \\
\hline 7 Avelgem & Rodenhuize & 380 & 9026 & 1420 & Y \\
\hline 8 Avelgem & Zomergem & 380 & 12234 & 1350 & Y \\
\hline 9 Borssele (NL) & Zandvliet & 380 & 10931 & 1650 & \\
\hline 10 Bruegel & Buggenhout & 380 & 30545 & 1420 & $\mathrm{Y}$ \\
\hline 11 Bruegel & Buggenhout & 380 & 31090 & 1350 & Y \\
\hline 12 Bruegel & Courcelles 2 & 380 & 10268 & 1420 & Y \\
\hline 13 Bruegel & Mekingen & 380 & 34468 & 1350 & Y \\
\hline 14 Brume & Coo & 380 & 242820 & 1350 & Y \\
\hline 15 Brume & Coo & 380 & 242820 & 1350 & Y \\
\hline 16 Brume & Gramme & 380 & 10963 & 1420 & Y \\
\hline 17 Brume & Gramme & 380 & 10963 & 1350 & Y \\
\hline 18 Buggenhout & Mercator & 380 & 31332 & 1420 & Y \\
\hline 19 Buggenhout & Mercator & 380 & 31780 & 1350 & Y \\
\hline 20 Buggenhout & Verbrande Brug & 380 & 22372 & 1420 & Y \\
\hline 21 Buggenhout & Verbrande Brug & 380 & 22372 & 1420 & Y \\
\hline 22 Champion & Cognelee & 380 & 134987 & 1420 & \\
\hline 23 Cognelee & Courcelles 2 & 380 & 11991 & 1420 & Y \\
\hline 24 Cognelee & Gramme & 380 & 16982 & 1420 & Y \\
\hline 25 Courcelles 1 & Gouy & 380 & 284443 & 1350 & Y \\
\hline 26 Courcelles 1 & Mekingen & 380 & 14534 & 1350 & Y \\
\hline 27 Courcelles 1 & StAmand & 380 & 38569 & 1350 & Y \\
\hline 28 Courcelles 2 & Gouy & 380 & 269973 & 1420 & Y \\
\hline 29 Doel 1 & Mercator & 380 & 23241 & 1420 & Y \\
\hline 30 Doel 1 & Mercator & 380 & 21295 & 1350 & Y \\
\hline 31 Doel 2 & Mercator & 380 & 21295 & 1350 & Y \\
\hline 32 Doel 2 & Zandvliet & 380 & 66471 & 1420 & Y \\
\hline 33 Doel 2 & Zomergem & 380 & 7048 & 1350 & Y \\
\hline 34 Drogenbos & Mekingen & 380 & 47128 & 1420 & \\
\hline 35 Eeklo Noord & Zomergem & 380 & 40429 & 1420 & \\
\hline 36 Geert & Zandvliet & 380 & 8596 & 1650 & \\
\hline 37 Gramme & Herderen & 380 & 11391 & 1350 & Y \\
\hline 38 Gramme & Rimiere & 380 & 33255 & 1350 & Y \\
\hline 39 Gramme & Saint Amand & 380 & 8610 & 1350 & Y \\
\hline 40 Gramme & Tihange & 380 & 147492 & 1420 & Y \\
\hline 41 Gramme & Tihange & 380 & 186733 & 1420 & Y \\
\hline 42 Gramme & Tihange & 380 & 167687 & 1350 & Y \\
\hline 43 Gramme & Tihange & 380 & 167687 & 1350 & Y \\
\hline 44 Herderen & Lixhe & 380 & 47621 & 1420 & Y \\
\hline 45 Herderen & Maasbracht (NL) & 380 & 9138 & 1350 & \\
\hline 46 Lint & Massenhoven & 380 & 34441 & 1420 & Y \\
\hline 47 Lint & Mercator & 380 & 23019 & 1420 & Y \\
\hline 48 Lint & Mercator & 380 & 23019 & 1420 & Y \\
\hline 49 Maasbracht (NL) & Meerhout & 380 & 6998 & 1420 & \\
\hline 50 Massenhoven & Meerhout & 380 & 14942 & 1420 & Y \\
\hline 51 Massenhoven & Mercator & 380 & 13797 & 1420 & Y \\
\hline 52 Mercator & Rodenhuize & 380 & 14204 & 1350 & $\mathrm{Y}$ \\
\hline 53 Saint Amand & Tergnee & 380 & 64753 & 1420 & \\
\hline
\end{tabular}

Table 1: Lines used in the numerical model. 


\begin{tabular}{|c|c|c|c|c|c|}
\hline \multirow[b]{2}{*}{ \# line FROM } & \multirow[b]{2}{*}{ то } & \multirow{2}{*}{$\begin{array}{r}V \\
(k V)\end{array}$} & \multicolumn{2}{|c|}{$\mathbf{Y} \bar{Q}_{i}$} & \multirow{2}{*}{$\begin{array}{c}\mathrm{N}-1 \\
\text { (Yes) }\end{array}$} \\
\hline & & & (p.u.) & $(\mathrm{MW})$ & \\
\hline 54 Aubange & Belval & 220 & 8601 & 400 & \\
\hline 55 Aubange & Heinsch & 220 & 11686 & 240 & \\
\hline 56 Aubange & Latour & 220 & 8534 & 345 & \\
\hline 57 Aubange & Moula & 220 & 8839 & 400 & \\
\hline 58 Aubange & StMard & 220 & 6269 & 345 & \\
\hline 59 Aubange & Villeroux & 220 & 3644 & 240 & \\
\hline 60 Awirs & Le Val & 220 & 20157 & 410 & \\
\hline 61 Awirs & Rimiere & 220 & 18398 & 375 & \\
\hline 62 Brume & Montlez Houffalize & 220 & 6462 & 510 & \\
\hline 63 Harnoncourt & Saint Mard & 220 & 188066 & 345 & \\
\hline 64 Heinsch & Villeroux & 220 & 5339 & 240 & \\
\hline 65 Jupille & Lixhe & 220 & 14885 & 541 & \\
\hline 66 Jupille & Rimiere & 220 & 5963 & 410 & \\
\hline 67 Jupille & Romsee & 220 & 23987 & 300 & \\
\hline 68 Latour & Sint Mard & 220 & 23716 & 345 & \\
\hline 69 La Troque & Seraing & 220 & 53081 & 400 & \\
\hline 70 La Troque & Seraing & 220 & 53081 & 400 & \\
\hline 71 Le Val & Rimiere & 220 & 10012 & 375 & \\
\hline 72 Le Val & Seraing & 220 & 45360 & 400 & \\
\hline 73 Marcourt & Rimiere & 220 & 4567 & 405 & \\
\hline 74 Marcourt & Villeroux & 220 & 5887 & 405 & \\
\hline 75 Montlez Houffalize & Villeroux & 220 & 6994 & 510 & \\
\hline 76 Rimiere & Seraing & 220 & 11467 & 400 & \\
\hline 77 Romsee & Seraing & 220 & 9138 & 400 & \\
\hline 78 Borssele (NL) & Geertruidenberg (NL) & 380 & 17168 & 946 & \\
\hline 79 Eindhoven (NL) & Geertruidenberg (NL) & 380 & 8237 & 1892 & \\
\hline 80 Eindhoven (NL) & Geertruidenberg (NL) & 380 & 8237 & 1892 & \\
\hline 81 Eindhoven (NL) & Geertruidenberg (NL) & 380 & 8237 & 1892 & \\
\hline 82 Eindhoven (NL) & Maasbracht (NL) & 380 & 11885 & 1892 & \\
\hline 83 Eindhoven (NL) & Maasbracht (NL) & 380 & 11885 & 1892 & \\
\hline 84 Lonny (FR) & Mastaing (FR) & 380 & 4236 & 1715 & \\
\hline 85 Lonny (FR) & Moulaine (FR) & 380 & 5267 & 2577 & \\
\hline 86 Lonny (FR) & Moulaine (FR) & 380 & 5267 & 2577 & \\
\hline 87 Avelin (FR) & Lonny (FR) & 380 & 3877 & 2570 & \\
\hline 88 Avelin (FR) & Lonny (FR) & 380 & 3877 & 2570 & \\
\hline 89 Avelin (FR) & Mastaing (FR) & 380 & 15701 & 1715 & \\
\hline 90 Avelin (FR) & Mastaing (FR) & 380 & 4297 & 496 & \\
\hline 91 Avelin (FR) & Mastaing (FR) & 380 & 2589 & 11499 & \\
\hline 92 Avelgem & Gouy & 150 & 1453 & 400 & \\
\hline
\end{tabular}

Table 1: (Continued) Lines used in the numerical model. 


\subsection{Electricity generation}

Table 2 summarizes relevant data on the 51 generation units located in the grid. Total available generation capacity equals 13405 MW. The data are based upon the year 2002. ${ }^{11}$

The first column gives the node at which the generation unit is attached, the second the name of the plant, and the third the fuel type of the plant. The columns four and five give the marginal cost parameter $C_{g}$ (defined below) and the maximal capacity of the plants $\bar{q}_{g}$.

In the simulations, three alternative scenarios are considered w.r.t. the functioning of the generation market. First, we assume a generation monopoly, i.e. all generation units are owned by one profit maximizing generator. The second scenario considers three profit maximizing generators, having an approximate market share in generation capacity of $43 \%, 34 \%$ and $23 \%$, respectively. The last column in Table 3 provides information on the assumed generation ownership structure in this case. Finally, the third scenario assumes perfect competition in generation.

Approximately $1070 \mathrm{MW}$ of smaller generation plants are not included in the model. These are mainly combined heat and power generation units (970 MW), and some small hydro units $(90 \mathrm{MW})$. We assume that in any time period, $50 \%$ of these plants produce electricity.

Each player maximizes profit, taking into account plant characteristics. Generation decisions are described by the first order conditions 5 . The player's generation decisions are highly non-linear at the zero production level and at the maximal capacity of each plant. Therefore, the model in this paper is a Mathematical Program with Equilibrium Constraints. (MPEC's) MPECs are a class of problems which are known to be difficult to solve. (Luo, Pang, Ralph, 1996). This paper uses a pragmatic approach to solve them and smoothes the marginal cost function of the generators.

In the model, marginal costs are defined as

$$
\frac{\partial C_{g}^{p}\left(q_{g}\right)}{\partial q_{g}}=C_{g} \cdot\left[1-\alpha_{g}\left(\beta_{g}+\frac{q_{g}}{\bar{q}_{g}}\right)^{-\phi_{g}}+\alpha_{g}\left(\beta_{g}+\frac{\bar{q}_{g}-q_{g}}{\bar{q}_{g}}\right)^{-\phi_{g}}\right]
$$

with $\bar{q}_{g}$ denoting the production capacity of production plant $g$, and $C_{g}$ is the marginal cost of generation when $50 \%$ of the generation capacity of plant $g$ is used. The parameters $\alpha_{g}, \phi_{g}$, $\beta_{g}$ are chosen such that generators always choose an internal solution. All this will be at the cost of accuracy concerning the exact value of the marginal cost, but the numerical problem becomes much easier to solve and we will be more sure to find a solution close to the global optimum.

The total generation cost is the integral of the marginal cost function, i.e.

$$
C_{g}\left(q_{g}\right)=\int_{o}^{q_{g}} \frac{\partial C_{g}(t)}{\partial q_{g}} d t
$$

\footnotetext{
${ }^{11}$ Some of the data was kindly provided by Leonardo Meeus and Kris Voorspools of the Departments of Electrical and Mechanical Engineering, respectively. Data was also taken from several editions of the BFE statistical yearbook, the annual report of Electabel.
} 


\begin{tabular}{|c|c|c|c|c|c|c|}
\hline \# gen & Node & Name Plant & Fuel Type & $\begin{array}{c}C_{g} \\
\left(€ \mathbf{M W h}^{-1}\right)\end{array}$ & $\begin{array}{r}\bar{q}_{g} \\
\text { (MW) }\end{array}$ & $f$ \\
\hline 1 & Avelgem & Ruien 3 & Conv. Coal & 20 & 152 & $\overline{3}$ \\
\hline 2 & Avelgem & Ruien 4 & Conv. Coal & 20 & 158 & 3 \\
\hline 3 & Avelgem & Ruien 6 & Conv. Coal & 20 & 236 & 3 \\
\hline 4 & Avelgem & Ruien 5 & Conv. Coal + repower. & 19 & 238 & 3 \\
\hline 5 & Avelgem & Ruien 7 & Conv. Coal + repower. & 19 & 95 & 3 \\
\hline 6 & Awirs & Awirs 4 & Conv. Coal & 20 & 124 & 3 \\
\hline 7 & Bruegel & Deux-Acren & Turbojets & 59 & 18 & 3 \\
\hline 8 & Coo & Cool & Pumped Storage & 13 & 474 & 2 \\
\hline 9 & Coo & Coo II & Pumped Storage & 13 & 690 & 2 \\
\hline 10 & Coo & Cierreux & Turbojets & 59 & 17 & 3 \\
\hline 11 & Doel 1 & Doel 2 & Nuclear & 10 & 393 & 1 \\
\hline 12 & Doel 1 & Doel 4 & Nuclear & 10 & 985 & 1 \\
\hline 13 & Doel 2 & Doel 1 & Nuclear & 10 & 393 & 1 \\
\hline 14 & Doel 2 & Doel 3 & Nuclear & 10 & 1006 & 1 \\
\hline 15 & Drogenbos & Drogenbos & STAG & 18 & 460 & 2 \\
\hline 16 & Drogenbos & Drogenbos & Gas Turbine & 45 & 78 & 3 \\
\hline 17 & Drogenbos & Ixelles & Turbojets & 59 & 18 & 3 \\
\hline 18 & Eeklo Noord & Brugge Herdersbrug & STAG & 18 & 460 & 2 \\
\hline 19 & Eeklo Noord & Zedelgem & Turbojets & 59 & 18 & 3 \\
\hline 20 & Eeklo Noord & Zeebrugge & Turbojets & 59 & 18 & 3 \\
\hline 21 & EekloNoord & Aalter & Turbojets & 59 & 18 & 3 \\
\hline 22 & Gouy & Saint-Ghislain & STAG & 18 & 350 & 2 \\
\hline 23 & Gouy & Amercoeur 2 & Conv. Coal & 20 & 127 & 3 \\
\hline 24 & Gouy & Monceau & Conv. Coal & 20 & 92 & 3 \\
\hline 25 & Gouy & Plate tail & Pumped Storage & 13 & 143 & 2 \\
\hline 26 & Herderen & Langerlo 1 & Conv. Coal + repower. & 19 & 301 & 2 \\
\hline 27 & Herderen & Langerlo 2 & Conv. Coal + repower. & 19 & 301 & 2 \\
\hline 28 & Izegem & Harelbeke & Diesel Motor & 58 & 77 & 3 \\
\hline 29 & Izegem & Noorschote & Turbojets & 59 & 18 & 3 \\
\hline 30 & Jupille & Monsin & Gas Turbine & 45 & 70 & 3 \\
\hline 31 & LaTroque & Angleur 1 en 3 (Socolie) & STAG & 18 & 121 & 2 \\
\hline 32 & LeVal & Seraing & STAG & 18 & 460 & 2 \\
\hline 33 & Massenhoven & Beerse & Turbojets & 59 & 32 & 3 \\
\hline 34 & Meerhout & Mol 11 & Conv. Coal & 20 & 124 & 3 \\
\hline 35 & Meerhout & Mol 12 & Conv. Coal & 20 & 131 & 3 \\
\hline 36 & Meerhout & Mol & Gas Turbine & 45 & 30 & 3 \\
\hline 37 & Mercator & Kallo 1 & Conv. Gas & 21 & 261 & 3 \\
\hline 38 & Mercator & Kallo 2 & Conv. Gas & 21 & 261 & 3 \\
\hline 39 & Rodenhuize & Gent (Ham) & STAG & 18 & 53 & 2 \\
\hline 40 & Rodenhuize & Gent (Ringvaart) & STAG & 18 & 385 & 2 \\
\hline 41 & Rodenhuize & Rodenhuize 2 & Conv. Fuel & 40 & 129 & 3 \\
\hline 42 & Rodenhuize & Rodenhuize 3 & Conv. Fuel & 40 & 128 & 3 \\
\hline 43 & Rodenhuize & Rodenhuize 4 & Conv. Coal & 20 & 269 & 3 \\
\hline 44 & Rodenhuize & Gent (Ham) & Diesel Motor & 58 & 71 & 3 \\
\hline 45 & Rodenhuize & Zelzate & Turbojets & 59 & 18 & 3 \\
\hline 46 & Romsee & Turon & Turbojets & 59 & 17 & 3 \\
\hline 47 & Tihange & Tihange 1 & nuclear & 10 & 962 & 1 \\
\hline 48 & Tihange & Tihange 2 & nuclear & 10 & 1008 & 1 \\
\hline 49 & Tihange & Tihange 3 & nuclear & 10 & 1015 & 1 \\
\hline 50 & Verbrande Brug & Vilvoorde & STAG & 18 & 385 & 2 \\
\hline 51 & Verbrande Brug & Schaerbeek & Turbojets & 59 & 18 & 3 \\
\hline
\end{tabular}

Table 2: Generation units 


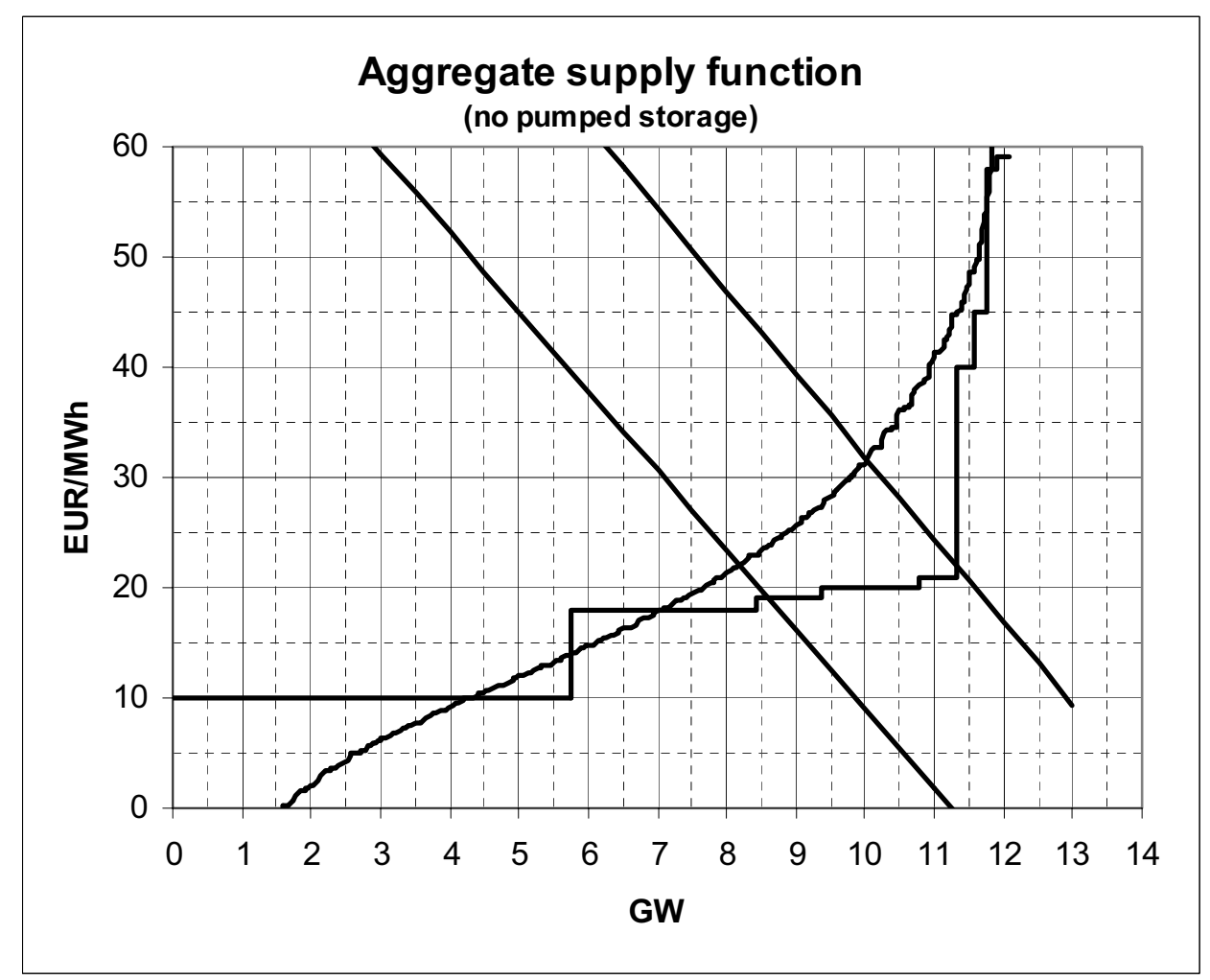

Figure 2: Aggregate supply function excluding pumped storage.

Plant numbers 8,9 and 24 are pumped storage plants, i.e. they can store energy in the form of a water reservoir. When generation costs are low, these plants consume electricity and pump water to a higher level. When generation costs are high, the reservoir is emptied and electricity is produced. The underlying decision process is not modelled in this paper. We assume that these plants generate electricity during peak periods at a marginal cost of $7 €$ per $M W h$, and we count them as part of the consumption side during the off-peak periods. ${ }^{12}$

Figures 2 and 3 show the aggregate supply function of the generation plants with and without the storage plants included. The stepped function is the real supply function, while the more or less fluent line is the approximated supply function. The approximation is reasonably close to the real supply function, for values of demand above $6 G W$.

\footnotetext{
${ }^{12} \mathrm{~A}$ better modelling of the pumped storage plants would require to take into account the capacity constraint of the water reservoir, and to make the decisions of whether to consume or to generate endogenous.
} 


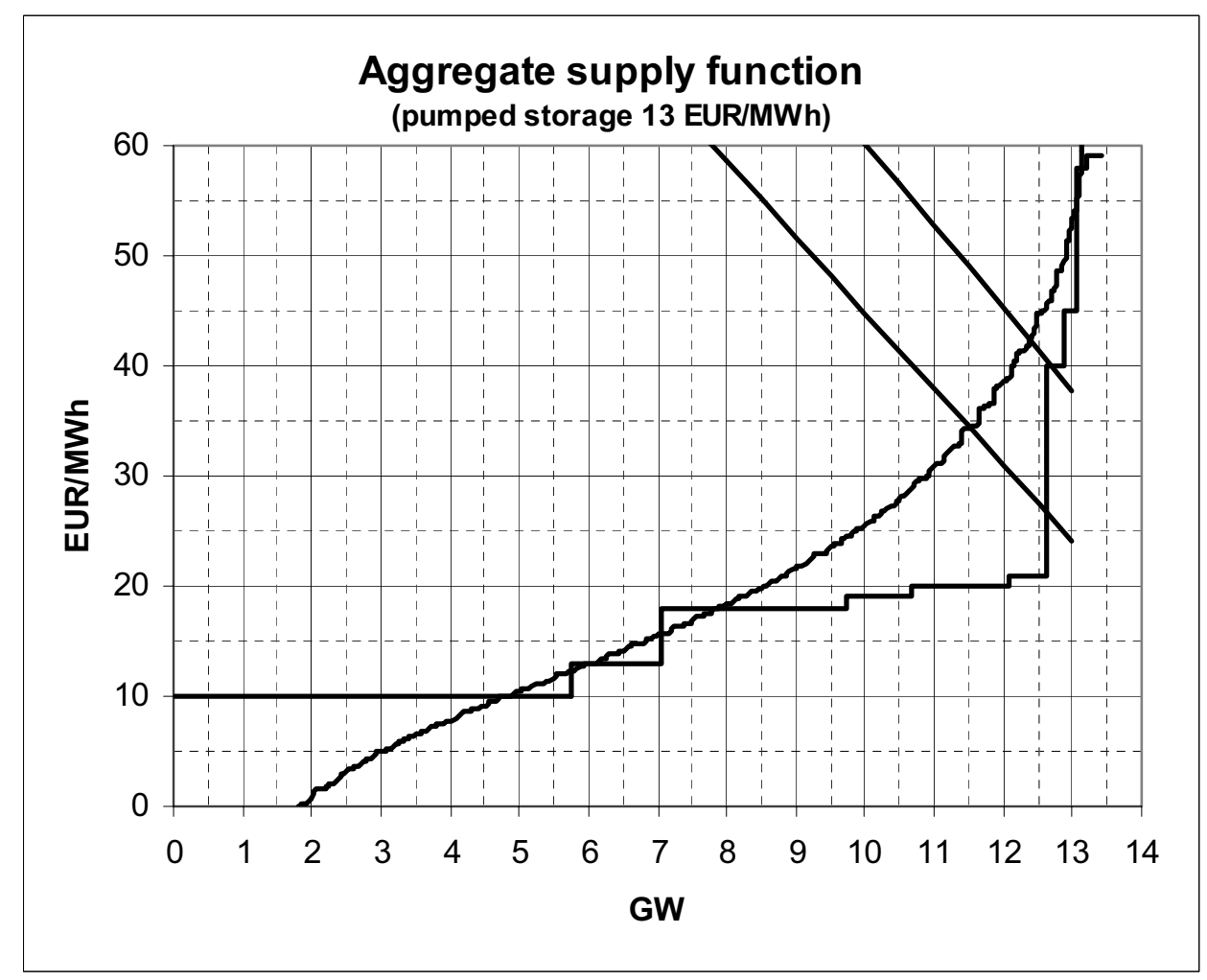

Figure 3: Aggregate supply function including pumped storage. 


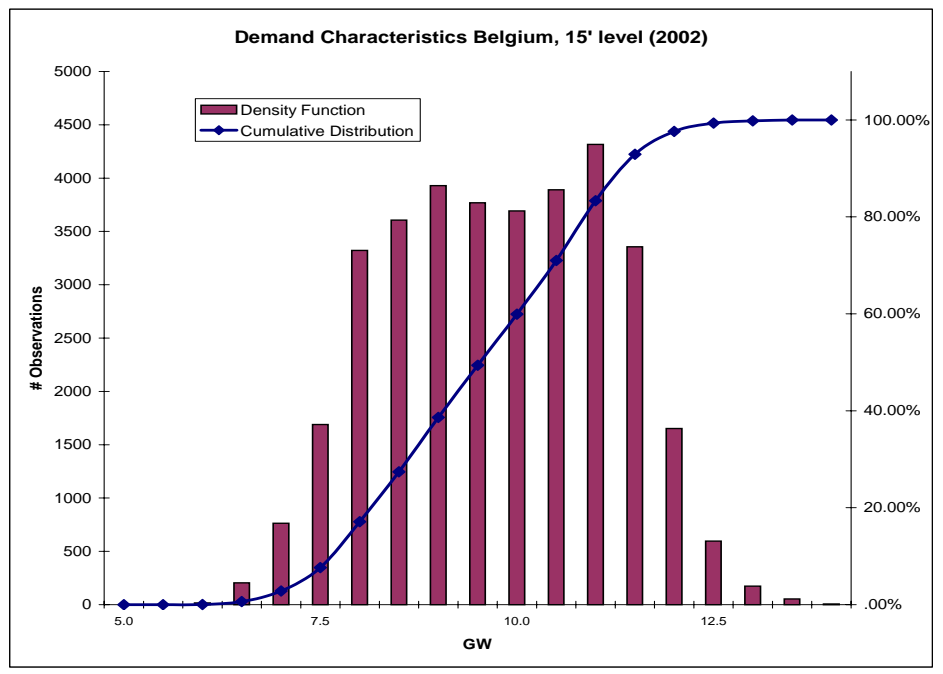

Figure 4: Histogram of electricity demand in Belgium in 2002. (Source ELIA)

\subsection{Electricity demand}

The model has been calibrated on the basis of Belgian data for electricity demand in $2002^{13}$. In that year the average demand was $9.52 \mathrm{GW}$. Total yearly demand in Belgium is 83.4 TWh per Year. Figure 4 presents a histogram of demand in Belgium. The histogram is based on periodical observations with a length of 15 minutes. The highest and lowest observed demand levels were $13.7 \mathrm{GW}$ and $5.8 \mathrm{GW}$, respectively.

Extending the model from one period to multi periods Obviously, the demand for electricity is not constant over time and in order to take this into account, the numerical one-period model has been extended to a 4-period model. For this, the model needs to be slightly extended, as one time period might have an effect on other time periods. In the present model, we distinguish three potential links.

First, cross-substitution can take place between time periods. For example, demand for electricity during the night will not only depend on the price in the night, but also on the price that is charged during the day. In this model it is assumed that these crosssubstitution effects are zero. There is thus no intertemporal substitution.

Second, as was mentioned before, the consumption and generation decision of the pumped storage plants can be endogenized. And finally, when the transmission firm is maximizing welfare subject to a budget constraint, then this budget constraint creates a

\footnotetext{
${ }^{13}$ The network of one part of Luxembourg forms an integral part of the Belgian network. Demand levels for that part are included in the model here.
} 


\begin{tabular}{|ccccc|}
\hline Period & $\begin{array}{l}\text { Demand } \\
\text { Observed } \\
\text { (GW) }\end{array}$ & $\begin{array}{c}\text { Period } \\
\text { Length }\end{array}$ & $\begin{array}{c}\text { Demand } \\
\text { Model } \\
\text { (GW) }\end{array}$ & $\begin{array}{c}\text { Reference } \\
\text { Price } \\
\text { [€/MWh] }\end{array}$ \\
\hline $\mathbf{1}$ & 12.5 & $2.4 \%$ & 12.0 & 45.2 \\
$\mathbf{2}$ & 11.5 & $20.1 \%$ & 11.0 & 37.9 \\
$\mathbf{3}$ & 10.0 & $38.9 \%$ & 9.5 & 35.6 \\
$\mathbf{4}$ & 8.0 & $38.6 \%$ & 7.5 & 27.0 \\
\hline
\end{tabular}

Table 3: Calibration of the 4 time periods

link between the different time periods. The marginal welfare cost of obtaining revenue for the network operator should now be equal over each time period.

Note that, if the network operator maximizes profit, then there is no (binding) budget constraint and the different time periods can be considered independently given the assumptions with respect to the two potential links discussed above.

\subsection{Network operator}

The network operator has total costs of $B=649 \mathrm{M} €$ per year (Source: Annual report ELIA, 2002). Capital costs are about $50 \%$ of the total costs, the other $50 \%$ being operating costs, such as wages and network maintenance costs. Wages and network maintenance costs are not directly related to the amount of MW transported over a line, they are inherent to the existence of that line. Therefore, as we could not find a more detailed description of the cost function of the network operator, we assume all costs to be fixed. Network losses are neglected in the model. Clearly, these would depend on the actual use of the network. With a total electricity demand of $83.4 T W h$ per year, the average cost of the network operator is $7.78 €$ per $M W h$.

\subsection{Calibration}

The calibration of the model involves three steps. Each of these three steps is described below.

Fixing periodic aggregate demand and the length of each period. The first step is to decide about the level of electricity demand in each of the four periods, and about the length of each period in a standard year. This has been done on the basis of the data presented in Figure 4. This figure shows how often a certain demand level occurs in the Belgian market. We will consider 4 periods with average demand levels fixed at 8, 10, 11.5 and $12.5 \mathrm{GW}$. The length of each time period is then set such that the cumulative distribution function of the 4 periods approximates the observed cumulative distribution function (Table 3). As $500 M W$ of this demand is provided by small generators, the demand level as seen by the generators in our model is fixed $500 \mathrm{MW}$ lower. Thus, the demand levels used to calibrate the demand functions are 7.5, 9.5, 11 and $12 G W$. 
Fixing a reference price for each period. Given the periodic electricity demand, derived in the first step, we minimize the production costs to supply this demand. Here, it is assumed that pumped water storage can only be used in period one and two. In the periods three and four, pumped storage plants pump water into a water reservoir.

Via this procedure, we obtain the marginal production cost for each period. The obtained values are increased with the average costs of the network operator $(7.78 €$ per $M W h$ ) to obtain a reference price for each period (Table 3).

Fixing periodic electricity demand in the consumption nodes In the third step, we derive for each node a linear demand function. The price elasticity of demand is assumed to be -0.5 in all nodes and all periods. Total demand is distributed proportionally over the different periods on the basis of the data in Table 4 and the reference prices calculated in step $2^{14}$. This information is sufficient to derive for each consumption node the parameters of the linear demand function.

\subsection{Transit}

It was already mentioned that the technical features and the dimension of the grid are inspired by the Belgian electricity market. Also, the generation and demand characteristics are based on data for Belgium. Therefore, we also take into account in our model that the Belgian grid is used for relatively large transit flows. These flows are generally directed from France to The Netherlands and, as a first approximation, we impose an exogenous transit flow of $1000 \mathrm{MW}$ from the south to the north. This transit is assumed to occur in all periods. The foreign generation and load nodes are summarized in Table 5.

Import from France to Belgium is neglected. Without modelling the French generator(s), import cannot be included in our model in a sound way. Import is about $400 \mathrm{MW}$.

Clearly, this is only an approximation. A more detailed and better modelling procedure should be the subject of further research.

\section{Simulation results}

This section discusses some simulation results obtained with the model. However, before starting the discussion, we first try to grasp some intuition on the setting of and relation between the transmission charges for consumers and generators. Then, in subsection 2 , we discuss the simulation results obtained in a one period model, under the assumption that

- demand is low;

- the transmission firm maximizes welfare (with budget constraint (second best) and without (first best) );

\footnotetext{
${ }^{14}$ Data is based on Van Roy (2001).
} 


\begin{tabular}{|c|c|c|}
\hline \# Cons & Node & MWh \\
\hline 1 & Gouy & 780 \\
\hline 2 & Lint & 746 \\
\hline 3 & Verbrande Brug & 690 \\
\hline 4 & Bruegel & 661 \\
\hline 5 & Zandvliet & 618 \\
\hline 6 & Gramme & 579 \\
\hline 7 & Izegem & 526 \\
\hline 8 & Meerhout & 508 \\
\hline 9 & Tergnee & 471 \\
\hline 10 & Massenhoven & 432 \\
\hline 11 & Seraing & 378 \\
\hline 12 & Lixhe & 350 \\
\hline 13 & Belval & 341 \\
\hline 14 & Mercator & 329 \\
\hline 15 & Achene & 286 \\
\hline 16 & Awirs & 281 \\
\hline 17 & Champion & 254 \\
\hline 18 & Rimiere & 229 \\
\hline 19 & Aubange & 226 \\
\hline 20 & Jupille & 223 \\
\hline 21 & Romsee & 165 \\
\hline 22 & La Troque & 125 \\
\hline 23 & Rodenhuize & 123 \\
\hline 24 & Avelgem & 116 \\
\hline 25 & Villeroux & 95 \\
\hline 26 & Montlez Houffalize & 94 \\
\hline 27 & Drogenbos & 84 \\
\hline 28 & Marcourt & 83 \\
\hline 29 & Heinsch & 60 \\
\hline 30 & Harnoncourt & 57 \\
\hline 31 & Eeklo Noord & 34 \\
\hline 32 & Brume & 25 \\
\hline 33 & Saint Mard & 14 \\
\hline 34 & Latour & 14 \\
\hline
\end{tabular}

Table 4: Distribution of demand over the different nodes when total demand is $10000 \mathrm{MW}$

\begin{tabular}{|c|c|}
\hline \multicolumn{2}{|l|}{ The Netherlands } \\
\hline Node & [MW] \\
\hline Maasbracht (NL) & -731 \\
\hline Geertruidenberg (NL) & -368 \\
\hline Borssele (NL) & 99 \\
\hline TOTAL & -1000 \\
\hline \multicolumn{2}{|l|}{ France } \\
\hline Node & [MW] \\
\hline Aveli (FR) & 543 \\
\hline Lonny (FR) & 34 \\
\hline Moulaine (FR) & 423 \\
\hline TOTAL & 1000 \\
\hline
\end{tabular}

Table 5: Exogenous generation levels at the foreign nodes. Negative numbers are loads. 
- the generation market is perfectly competitive;

- security constraints are neglected.

Subsection 3 then discusses simulation results obtained under the same assumptions except that now a high demand is assumed. Subsection 4 discusses the same scenario's as in subsection 3, but now the $n-1$ rule is imposed as a security of supply constraint.

Finally, subsection 5 introduces the multi-period approach, considers alternative objective functions for the transmission company and alternative market structures for electricity generation. The impact of these alternatives on the market outcome will be discussed.

One final remark has to be made. The simulations presented in this paper serve the purpose of illustrating the possibilities of the model. The current simulation results do not pretend to give a fully realistic view of what would be the outcome for the Belgian electricity market if the liberalization process is finalized. But we do feel that the model has the potential to provide insight in the consequences of such structural and regulatory changes. However, this would require a more detailed modelling, especially of the regulatory settings.

\subsection{Interpreting transmission prices}

In the current model, we assume that the network operator is able to set a transmission price for generation and consumption in each node: $\tau_{i}^{p}$ and $\tau_{i}^{c}$. Within the set of linear price structures, this is the most general assumption. It encompasses a number of 'price structure' options as special cases. For example, only charging consumption, only charging generation, a separate but uniform tariff for generation and consumption and, one uniform tariff for both generation and consumption as the most extreme case. In the simulations presented in this paper, we stick to the most general case which means that the network operator has the freedom to set differentiated charges for generation and consumption.

However, the optimal transmission charges are not uniquely defined. First, take a node $i$ at which no consumers are connected. For that node, the consumer transmission price $\tau_{i}^{c}$ does not play a role and it can safely be set equal to zero. The same is true for nodes without generation. Here, $\tau_{i}^{p}$ is not uniquely defined and the charge is set equal to zero.

Second, note that a firm generating electricity in node $i$, that is sold in node $j$, has to pay a per unit transmission charge equal to

$$
\tau_{i j}=\tau_{i}^{p}+\tau_{j}^{c}
$$

For the generation firm, only the total transmission charge is important, not its exact composition. The network operator has therefore one degree of freedom in setting the transmission charge components. This can easily be checked from the equations 19 and 20, and by noting that one can uniformly increase all generation tariffs with $t$ and decrease all consumer tariffs with $t$ without changing the sum of the charges. Indeed, the new tariffs 
$\tau_{i}^{c *}$ and $\tau_{i}^{p *}$ will equal

$$
\begin{aligned}
\tau_{i}^{c *} & =\tau_{i}^{c}-t \\
\tau_{i}^{p *} & =\tau_{i}^{p}+t
\end{aligned}
$$

but the total charge for transmission between any two nodes $i$, and $j$ remains the same, i.e. $\tau_{i j}=\tau_{i j}^{*}$. We can therefore arbitrarily fix the consumers' transmission price in one node equal to zero. This is done for the consumption charge in the swing node:

$$
\tau_{i}^{c}=0 \quad i=\text { swing node }
$$

Finally, note that the model implicitly assumes that the charges need to be paid for all consumption and generation, even if generation and consumption is located at the same node. A generator in node $i$ who sells electricity locally does not use the transmission network, but will have to pay a transmission payment $\tau_{i i}=\tau_{i}^{c}+\tau_{i}^{p}$. We will call this charge the price wedge, because this charge creates a wedge between the consumer price and the generator price in node $i^{15}$.

The next subsection continues with a discussion of the simulation exercises.

\subsection{Low demand - No security of supply constraints}

This simulation scenario assumes low demand (off-peak), no security of supply considerations and welfare maximizing behavior at the side of the network operator. Due to the low demand assumption, congestion is not an issue. The results can be interpreted as being the results for running the electricity system in an off-peak period of one hour.

Two scenarios are compared, the first best and the second best. In the first best scenario, competition in the generation market is perfect and the network operator maximizes welfare without facing a budget constraint. The second best scenario is identical to the first best scenario except that now the network operator maximizes welfare subject to a budget constraint.

It is assumed that the network operator needs to obtain the same revenue in each hour of the year, that is $74087(=649 \mathrm{M} € / 8760 h) €$ per hour. In subsection 5 this assumption will be relaxed when we use the 4-period model.

Table 6 shows the simulation results for the first best and the second best cases in terms of welfare, surpluses for the economic agents, the network operator costs, generation (and consumption) level and the multiplier of the budget constraint. Quantities are expressed in MW, but since the simulations cover a 1 hour period, they can also be interpreted as MWh. Monetary values are expressed in million euro per hour.

In the first best scenario, generation is equal to $8223 \mathrm{MW}$. Consumer and producer surpluses are $243 \mathrm{k} €$ and $117 \mathrm{k} €$, respectively. Aggregate welfare, being the sum of these values and the surplus generated by the network operator $-74 \mathrm{k} €$ equals $287 \mathrm{k} €$.

\footnotetext{
${ }^{15}$ With imperfect competition, the generator price is not defined.
} 


\begin{tabular}{|lr|r|r|}
\hline Low Demand & 1st Best & 2nd Best & Rel. Change \\
\hline Welfare $(\mathrm{k} € / \mathrm{hr})$ & 287 & $\mathbf{2 8 2}$ & $101.6 \%$ \\
Consumer Surplus $(\mathrm{k} € / \mathrm{hr})$ & 243 & $\mathbf{1 9 3}$ & $126.4 \%$ \\
Producer Surplus $(\mathrm{k} € / \mathrm{hr})$ & 117 & $\mathbf{8 9}$ & $131.3 \%$ \\
Profit Network Operator $(\mathrm{k} € / \mathrm{hr})$ & -74 & $\mathbf{0}$ & - \\
Revenue Network Operator $(\mathrm{k} € / \mathrm{hr})$ & 0 & $\mathbf{7 4}$ & $0.0 \%$ \\
Fixed Cost Network Operator $(\mathrm{k} € / \mathrm{hr})$ & 74 & $\mathbf{7 4}$ & $100.0 \%$ \\
Multiplier Budget constraint $(€ / €)$ & 0.000 & $\mathbf{0 . 1 4 9}$ & - \\
Total Consumption $(\mathrm{MWh} / \mathrm{hr})$ & 8223 & $\mathbf{7 3 1 5}$ & $112.4 \%$ \\
\hline
\end{tabular}

Table 6: Period 4: Low demand without n-1 security constraints

Congestion on the grid is not an issue in this simulation and, therefore, the transmission charges for consumption and generation are set equal to zero, i.e.

$$
\tau_{i}^{p}=\tau_{i}^{c}=0
$$

The network operator is maximizing welfare and setting non-zero transmission charges would create distortions without any need. As transmission is for free, there will be a uniform end-user price for electricity in the Belgian market.

In the second best case, the network operator will set non-zero transmission charges to obtain sufficient revenue to cover his costs. Standard Ramsey pricing will be used to obtain this revenue. Transmission charges $\left(\tau_{i}^{c}, \tau_{i}^{g}\right)$ are set inversely proportional to the demand, resp. supply elasticity in each node ${ }^{16}$. The total deadweight loss in the market is minimized. Compared with the first best, the distortions in the reference scenario create a total welfare loss of $1.6 \%$. At the margin, generating $100 €$ extra revenue for the network operator creates a deadweight loss of $14.9 €$.

In this second best scenario, the end user prices will generally be higher than in the first best case. As a result, demand and generation $(7315 \mathrm{MW})$ will be lower than in the first best case $(8223 M W)$. Higher end user prices imply a lower consumer surpluses, but also the surplus of the generators (their profit) reduces due to the transmission charges.

\subsection{High demand - No security of supply constraints}

This subsection compares the first best and the second best in the case of high demand. It neglects the $n-1$ security constraints. These constraints will be added in the next subsection.

If the network operator would set all transmission charges equal to zero in the first best, then the network capacity would be insufficient to satisfy the demand for transmission. Thus, congestion is an issue. Therefore, the network use must be charged in order to solve capacity problems. The charges should be chosen such that distortions are minimized. The best way to do this is to tax the effective use of the network, but not the 'intra-nodal' trade,

\footnotetext{
${ }^{16}$ Because demand is linear and, by construction, has the same intercept in all nodes, elasticities are identical in each node. As a consequence, all consumers face the same consumer charge.

The level and shapes of the marginal generation cost functions are different and therefore, different charges are set at different nodes.
} 


\begin{tabular}{|lr|r|r|}
\hline High Demand & 1st Best & 2nd Best & Rel. Change \\
\hline Welfare $(\mathrm{k} € / \mathrm{hr})$ & 865 & $\mathbf{8 6 4}$ & $100.1 \%$ \\
Consumer Surplus $(\mathrm{k} € / \mathrm{hr})$ & 581 & $\mathbf{5 5 6}$ & $104.5 \%$ \\
Producer Surplus $(\mathrm{k} € / \mathrm{hr})$ & 352 & $\mathbf{3 0 8}$ & $114.2 \%$ \\
Profit Network Operator $(\mathrm{k} € / \mathrm{hr})$ & -68 & $\mathbf{0}$ & - \\
Revenue Network Operator $(\mathrm{k} € / \mathrm{hr})$ & 6 & $\mathbf{7 4}$ & $8.5 \%$ \\
Fixed Cost Network Operator $(\mathrm{k} € / \mathrm{hr})$ & 74 & $\mathbf{7 4}$ & $100.0 \%$ \\
Multiplier Budget constraint $(€ / €)$ & 0.000 & $\mathbf{0 . 0 2 5}$ & - \\
Total Consumption $(\mathrm{MWh} / \mathrm{hr})$ & 12413 & $\mathbf{1 2 1 4 6}$ & $102.2 \%$ \\
\hline
\end{tabular}

Table 7: Period 1: High demand without n-1 security constraints.

i.e. the network operator will set the price wedge equal to zero, i.e. $\tau_{i i}=0\left(\tau_{i}^{c}=-\tau_{i}^{p}\right)$. The reason for this is simple: setting a positive price wedge $\tau_{i i}=\tau_{i}^{c}+\tau_{i}^{p}>0$, increases the distortion in the local market at node $i$, but only has an indirect effect on the network flows that cause the congestion. Therefore, it is best to set the price wedge equal to zero. Note that this only makes sense for nodes at which both generators and consumers are connected. Otherwise the price wedge does not play a role.

These congestion charges allow the network operator to collect a revenue equal to 8.5 percents of the fixed costs (Table 7). In the second best case, the network operator needs to increase transmission charges from their first best level, in order to obtain sufficient revenue for the remaining $91.5 \%(=100 \%-8.5 \%)$ of his budget.

Note that the impact of adding the budget constraint (second best versus first best) on welfare and on the distribution of the surpluses is relatively small compared to its impact in the 'low-demand' scenario. The reason is that, in this scenario, congestion occurs in the fist as well as in the second best case. Once congestion is 'solved', the additional distortions resulting from setting transmission charges that satisfy the revenue constraint are small.

\subsection{High Demand - With security of supply constraints}

In this scenario, $n-1$ security constraints are added. The results are shown in Table 8 .

Compared to the previous simulation exercise, the available transmission capacity has reduced, thus congestion will be a larger issue than it was in section 3. However, on the basis of a comparison of these two scenarios, its impact seems to be rather limited. The first best, transmission charges will on average be higher in order to solve the congestion problem, but apparently the charges have been changed primarily in a way that reshuffles generation (and consumption) over the network without reducing total production. The network operator's revenue via congestion charges is now sufficient to cover $67.5 \%$ of the costs. As revenue generation is not an objective for the network operator in the first best case, he still minimizes distortions and sets $\tau_{i}^{p}=-\tau_{i}^{c}$

In the second best case, the network operator increases transmission prices from their first best level, to cover the remaining $32.5 \%(=100 \%-67.5 \%)$ of his costs.

Table 9 and 10 show which lines are binding under the two scenarios. If the line in the first column breaks down, the line in the second column will be loaded up to its thermal capacity. The last column shows the shadow price of the thermal constraint of the lines 


\begin{tabular}{|lr|r|r|}
\hline High Demand - Contingency & 1st Best & 2nd Best & Rel. Change \\
\hline Welfare $(\mathrm{k} € / \mathrm{hr})$ & 856 & $\mathbf{8 5 6}$ & $100.0 \%$ \\
Consumer Surplus $(\mathrm{k} € / \mathrm{hr})$ & 563 & $\mathbf{5 5 4}$ & $101.7 \%$ \\
Producer Surplus $(\mathrm{k} € / \mathrm{hr})$ & 316 & $\mathbf{3 0 1}$ & $105.0 \%$ \\
Profit Network Operator $(\mathrm{k} € / \mathrm{hr})$ & -24 & $\mathbf{0}$ & - \\
Revenue Network Operator $(\mathrm{k} € / \mathrm{hr})$ & 50 & $\mathbf{7 4}$ & $67.5 \%$ \\
Fixed Cost Network Operator $(\mathrm{k} € / \mathrm{hr})$ & 74 & $\mathbf{7 4}$ & $100.0 \%$ \\
Multiplier Budget constraint $(€ / €)$ & 0.000 & $\mathbf{0 . 0 1 0}$ & - \\
Total Consumption $(\mathrm{MWh} / \mathrm{hr})$ & 12141 & $\mathbf{1 2 0 4 4}$ & $100.8 \%$ \\
\hline
\end{tabular}

Table 8: Period 1: First best vs. Second best, Security constraints included.

First Best - High Demand
\begin{tabular}{|ll|ll|r|}
\hline IF this line breaks & \multicolumn{2}{|l|}{ THEN this line at limit } & Shadow Price \\
From & To & From & To & 20.3 \\
\hline Aubange & Moulain (FR) & Aubange & Brume & 4.7 \\
Doel 2 & Mercator & Doel 2 & Zandvliet & 19.3 \\
Jupille & Lixhe & Gramme & Rimiere & 53.3 \\
LeVal & Seraing & Herderen & Lixhe & \\
\hline
\end{tabular}

Table 9: Congested lines in the first best model

that become constrained.

It should be noted that the results largely depend on the assumed distribution of demand and better information is needed in order to get a more realistic prediction about congestion in practice. However, these simulations clearly illustrate that the $n-1$ security constraints are important in analyzing congestion.

The simulations discussed so far were intended to illustrate the impact of demand and of $n-1$ security constraints on the market outcome and on transmission charges. The next subsection goes one step further and introduces a multi-period setting, and alternative assumptions on the behavior of the generation and the network operator.

The congestion is in other locations than in Van Roy (2001). He found congestion on the $150 \mathrm{kV}$ network due to local over-production in the region Herderbrug - Rodenhuize. There are three reasons why the results are different:

1. We assume a constant demand distribution over the nodes of network for all time periods. Van Roy models the distribution of demand more detailed;

2. Our model does not include the $150 \mathrm{kV}$ transmission lines;

Second Best - High Demand

\begin{tabular}{|c|c|c|c|c|}
\hline \multicolumn{2}{|c|}{ IF this line breaks } & \multicolumn{2}{|c|}{ THEN this line at limit } & \multirow{2}{*}{$\begin{array}{c}\text { Shadow Price } \\
{[€ / M W]}\end{array}$} \\
\hline From & To & From & To & \\
\hline Aubange & Moulain (FR) & Aubange & Brume & 19.4 \\
\hline Doel 2 & Mercator & Doel 2 & Zandvliet & 2.9 \\
\hline Jupille & Lixhe & Gramme & Rimiere & 19.3 \\
\hline LeVal & Seraing & Herderen & Lixhe & 52.6 \\
\hline
\end{tabular}

Table 10: Congested lines in the second best model 


\begin{tabular}{|l|r|rrr|rrr|}
\hline All Periods - Contingency & 1st . Best & W - PC & W - CO & W - MO & P - PC & P- CO & P - MO \\
\hline Welfare (M€/yr) & 4031 & $\mathbf{4 0 1 2}$ & 3648 & 2920 & 2947 & 2334 & 1725 \\
Consumer Surplus (M€/yr) & 3047 & $\mathbf{2 7 0 8}$ & 1643 & 828 & 847 & 503 & 271 \\
Producer Surplus (M€/yr) & 1622 & $\mathbf{1 3 0 4}$ & 2006 & 2093 & 444 & 699 & 760 \\
Profit Network (M€/yr) & -638 & $\mathbf{0}$ & 0 & 0 & 1656 & 1132 & 694 \\
Revenue Network (M€/yr) & 11 & $\mathbf{6 4 9}$ & 649 & 649 & 2305 & 1781 & 1343 \\
Fixed Cost Network (M€/yr) & 649 & $\mathbf{6 4 9}$ & 649 & 649 & 649 & 649 & 649 \\
Multiplier Budget Network (€/€) & 0.000 & $\mathbf{0 . 0 7 0}$ & 0.373 & 0.706 & 0.000 & 0.000 & 0.000 \\
Total Consumption (GWh) & 84,998 & $\mathbf{8 0 , 1 2 0}$ & 62,258 & 44,178 & 44,676 & 34,374 & 25,252 \\
\hline
\end{tabular}

Table 11: Aggregate results of the 6 scenarios.

3. Van Roy assumes that production levels are exogenous, while they are exogenous in our model.

\subsection{A multi-period setting with strategic behavior of generators and the transmission firm}

We consider 6 scenarios. For the network operator we evaluate two assumptions with respect to his objective function: welfare maximization subject to a budget constraint (index ' $W$ '), and profit maximization (' $P$ '). For the generation market structure we evaluate three assumptions: perfect competition (' $P C^{\prime}$ '), Cournot competition ( ' $C O$ '), and monopoly ('MO'). The scenario $W-P C$ is in fact the second best scenario discussed in subsection 4 , except that now 4 periods are considered. Therefore, the simulation results are not immediately comparable. We will also report the results of the first best scenario, i.e. welfare maximization without a budget constraint. All simulations were made with the 4-period model and include the $n-1$ security constraints.

Table 11 presents the consumers surplus, generation profit, the revenue, the fixed costs, and the profit of the network operator, welfare and total generation for each scenario. In the scenarios with welfare maximization subject to a budget constraint, the multiplier of this constraint is also shown.

The results do not come as a surprise. Ceteris paribus, regulating the network operator and increasing competition in generation increases welfare.

The multiplier of the budget constraint of the network operator measures the net cost of giving one Euro to the network operator. The effect is about ten times as large with monopoly than with perfect competition. The reason for this is that in the monopoly case the distortion in the electricity market is already high, and obtaining extra revenue will increase this distortion even more.

Table 12 shows the same results as Table 11, but now they are expressed relative to the second best scenario.

What is the effect of regulating the network operator under the three alternative market structures for generation? Table 13 shows the effect of introducing perfect regulation of the network operator. Under perfect competition regulation increases welfare with $1065 \mathrm{M} €$. The profit of the network operator reduces with $1656 \mathrm{M} €$ and the consumers and the producers gain $1860 \mathrm{M} €$ and $860 \mathrm{M} €$ respectively. Total generation increases with 35.4 


\begin{tabular}{|l|r|rrr|rrr|}
\hline All Periods - Contingency & 1st . Best & W - PC & W - CO & W - MO & P - PC & P- CO & P - MO \\
\hline Welfare (\%) & 100.49 & $\mathbf{1 0 0 . 0 0}$ & 90.94 & 72.79 & 73.46 & 58.17 & 43.00 \\
Consumer Surplus (\%) & 112.53 & $\mathbf{1 0 0 . 0 0}$ & 60.66 & 30.56 & 31.30 & 18.58 & 10.00 \\
Producer Surplus (\%) & 124.39 & $\mathbf{1 0 0 . 0 0}$ & 153.83 & 160.50 & 34.02 & 53.58 & 58.30 \\
Profit Network (-) & - & - & - & - & - & - & - \\
Revenue Network (- ) & 1.75 & $\mathbf{1 0 0 . 0 0}$ & 100.00 & 100.00 & 355.13 & 274.39 & 206.94 \\
Fixed Cost Network (\%) & 100.00 & $\mathbf{1 0 0 . 0 0}$ & 100.00 & 100.00 & 100.00 & 100.00 & 100.00 \\
Multiplier Budget Network (- ) & - & - & - & - & - & - & - \\
Total Consumption (\%) & 106.09 & $\mathbf{1 0 0 . 0 0}$ & 77.71 & 55.14 & 55.76 & 42.90 & 31.52 \\
\hline
\end{tabular}

Table 12: Relative performance of the 6 scenarios. The Second Best situation (W - PC) is used as a reference.

\begin{tabular}{|l|ccr|}
\hline All Periods - Contingency & PC & CO & MO \\
\hline Welfare (M€/yr) & 1065 & 1315 & 1195 \\
Consumer Surplus $(\mathrm{M} € / \mathrm{yr})$ & 1860 & 1139 & 557 \\
Producer Surplus $(\mathrm{M} € / \mathrm{yr})$ & 860 & 1307 & 1332 \\
Profit Network (M€/yr) & -1656 & -1132 & -694 \\
Revenue Network (M€/yr) & -1656 & -1132 & -694 \\
Fixed Cost Network (M€/yr) & - & - & - \\
Multiplier Budget Network $(€ / €)$ & - & - & - \\
Total Consumption $(\mathrm{GWh})$ & 35444 & 27884 & 18926 \\
\hline
\end{tabular}

Table 13: Effect of regulation, for the three generation market structures.

TWh.

From the table we can learn that regulation increases welfare, and is most effective when there is Cournot competition in generation, and least effective if there is perfect competition. Regulation decreases the profit of the network operator. Generators and consumers share the increase in welfare. The sharing depends on the market structure of the generation market. In the monopoly case, the fruits of regulation go mainly to the monopolist. With perfect competition, the welfare gains go mainly to consumers.

Congestion in the network In the multi-period model, both the first best and the second best scenario have congestion in the peak period. In the other periods, demand for transmission is too low and there is no congestion.

\section{Conclusions}

This paper sets a first step in understanding the strategic behavior of a network operator via a numerical simulation model. It looks at the pricing behavior of the network operator in a market with transmission constraints and with imperfect competition in generation. Consumers are assumed to be price takers in the electricity market. Generators are Cournot players in production and sales, but they are price takers in the transmission market. The network operator is a Stackelberg leader and sets the transmission price before the generators decide about their production and sales.

The model is illustrated with some simulation runs. The parametrization of the model is inspired by the technical characteristics of the Belgian electricity system. It includes the 
Belgian high voltage transmission grid, and the most important lines in France and the Netherlands. The network is presented as a linearized DC-load flow model. Transmission is limited by the thermal constraints of the lines and $n-1$ security constraints are imposed. If one of the lines breaks down, then the remaining lines should be able to transport the electricity.

The model studies 6 scenarios. It assumes a perfectly regulated network operator who maximizes welfare subject to a budget constraint, and a non-regulated network operator who maximizes profit. For the generation sector, it considers 3 market structures: Perfect competition, Cournot competition, and a monopoly market.

Imperfect competition and a badly regulated transmission network both have the expected impact on welfare: they reduce it. (Perfect) regulation of the network operator has the largest impact if there is Cournot competition in generation and the smallest if the generation sector is competitive.

The paper illustrates that $n-1$ security constraints should be modelled if one wants to have an idea of the amount of congestion in the network.

The simulations presented in this paper are only intended to illustrate the possibilities of the model. In its current form, and eventually with some extensions, the model can be used to study many relevant policy issues concerning electricity markets. We give a short non-exhaustive survey of possible extensions and applications.

The ownership structure and the location of the firms in the grid might be important in determining the market power of the generators. If firms have geographically dispersed production capacities, the effect of congestion might be much smaller than when each firms is geographically concentrated.

Belgium is located between a low priced country (France) and the high price country (the Netherlands) and it serves as a transit country. The model in the paper, could be used to calculate the welfare impact of different levels of transit.

As most of the congestion on the Belgian network involves international transactions it would be interesting to also include the Dutch, the German, and the French generation markets and networks, as in Hobbs et al. (2002).

Consumers do not resell electricity and there is no arbitrage in the model. This could be included and its impact could be studied. Appendix A shows how arbitrage can be introduced in the model.

In the paper, we assumed that the generators are competing à la Cournot. A possible extension is to assume that generators compete with conjectured supply functions, as shown in Hobbs, Metzler, Pang (2000) and in Day Hobbs, Pang (2002).

The paper considers two extreme forms of regulation: no regulation and perfect regulation. Other types of regulation could be introduced. For example, the regulator could fix the average price over nodes and time periods while leaving the decisions about the (linear) tariff structure to the network operator. The model can also be used to study the welfare impact of alternative tariff structures, such as for example postage stamp tariffs.

To improve the modelling of the behavior of the network operator, his cost function should be specified as a function of the use of the transmission network and should allow for new investments in transmission lines. A welfare maximizing network operator might 
invest in more transmission capacity to increase competition in the generation market. A model for the regulation of the network operator can then also be based upon his costs.

\section{A Arbitrage}

The model of Smeers and Wei (1997) has been extended by Metzler et al. (2003) and Hobbs (2001) to include arbitrage. This appendix shows how arbitrage is introduced in the model presented in this paper.

An arbitrageur can be modelled as an extra generator with index $a \in F$ who has no generation capacity $G_{a}=\varnothing$, and who is price taker in both the energy and the transmission market.

The arbitrageur maximizes

$$
\max _{s_{a i}} \Pi^{a r b}=\sum_{i \in I}\left(p_{i}-\tau_{i}^{c}\right) \cdot s_{a i}
$$

Subject to:

$$
\sum_{i \in I} s_{a i}=0 \quad\left(\lambda_{a}^{p}\right)
$$

The first order conditions of the arbitrageur are the following:

$$
\left(p_{i}-\tau_{i}^{c}\right)=\lambda_{a}^{p} \quad \forall i \in I
$$

With arbitrage, the price difference between two nodes need to be equal to the differences in congestion charges for consumers.

$$
\left(p_{i}-p_{j}\right)-\left(\tau_{i}^{c}-\tau_{j}^{c}\right)=0
$$

Intuition: If the price $p_{i}$ is too high, arbitrageurs will buy electricity from consumers in region $j$. The value of this electricity for consumers in node $j$ is $p_{j}$. If consumers reduce consumption, they will save $\tau_{j}^{c}$ on their transmission bill. They will sell their electricity thus for a price $p_{j}-\tau_{j}^{c}$. The arbitrageur will sell the electricity to consumers in region $i$ at a price $p_{i}-\tau_{i}^{c}$. The consumers in region $j$ have to pay the congestion charge before consuming.

\section{References}

Bolle, F. (1992). Supply function equilibria and the danger of tacit collusion: the case of spot markets for electricity, Energy Economics 14: 94-102.

Borenstein, S., Bushnell, J. B. \& Knittel, C. R. (1999). Market power in electricity markets: Beyond concentration measures, Energy Journal 20: 65-88. 
Borenstein, S., Bushnell, J. B. \& Stoft, S. E. (1998). The competitive effects of transmission capacity in a deregulated electricity industry, Rand Journal of Economics 31: 294-325.

Boucher, J. \& Smeers, Y. (2002). Towards a common european electricity market; paths in the right direction: Still far from an effective design, Journal of Network Industries 3: $375-424$.

Cardell, J. B., Hitt, C. C. \& Hogan, W. W. (1997). Market power and strategic interaction in electricity networks, Resource and Energy Economics 19: 109-137.

Day, C. J., Hobbs, B. F. \& Pang, J. S. (2002). Oligopolistic competition in power networks: a conjectured supply function approach, IEEE Transactions on Power Systems 17: $597-607$.

Green, R. (1996). Increasing competition in the british electricity spot market, Journal of Industrial Economics 44: 205-216.

Green, R. \& Newbery, D. M. (1992). Competition in the British electricity spot market, Journal of Political Economy 100: 929-953.

Hobbs, B. F. (2001). Linear complementarity models of Nash-Cournot competition in bilateral and poolco power markets, IEEE Transactions on Power Systems 16: 194202.

Hobbs, B. F., Metzler, C. B. \& Pang, J. S. (2000). Strategic gaming analysis for electric power systems: an MPEC approach, IEEE Transactions on Power Systems 15: 638645 .

Hobbs, B. F., Rijkers, F. A. M., Wals, A. F. \& van Oostvoorn, F. (2002). Spatial oligopoly and transmission policy in the Benelux power markets: a conjectured supply function analysis, IAEE Aberdeen.

Hogan, W. W. (1997). A market power model with strategic interaction in electricity networks, Energy Journal 18: 107-141.

Klemperer, P. \& Meyer, M. (1989). Supply function equilibria in oligopoly under uncertainty, Econometrica 57: 1243-1277.

Metzler, C., Hobbs, B. F. \& J.S., P. (2003). Nash-Cournot equilibria in power markets on a linearized DC network with arbitrage: Formulations and properties, Networks and Spatial Economics 3: 123-150.

Newbery, D. M. (1998). Competition, contracts, and entry in the electricity spot market, Rand Journal of Economics 29: 726-749.

Oren, S. S. (1997). Economic inefficiency of passsive transmission rights in congested electricity systems with competitive generation, Energy Journal 18: 63-84. 
Rudkevich, A., Duckworth, M. \& Rosen, R. (1998). Modeling electricity pricing in a deregulated generation industry: the potential for oligopoly pricing in a Poolco., Energy Journal 19: 19-48.

Schweppe, F., Craramanis, M., Tabors, R. \& Bohn, R. (1988). Spot Pricing of Electricity, Kluwer Academic Publishers.

Smeers, Y. \& Wei, J. (1997). Spatially oligopolistic model with opportunity cost pricing for transmission capacity reservations - a variational approach, Louvain-La-Neuve, Number 9717.

Stoft, S. E. (1997). The effect of the transmission grid on market power, Berkeley, LBNL40479.

Van Roy, P. (2001). Study of the technical-economical aspects of the lberalisation of the electricity market, Leuven, PhD-Dissertation, Faculteit Toegepaste Wetenschappen, K.U.Leuven.

von der Fehr, N. \& Harbord, D. (1993). Spot market competition in the UK electricity industry, The Economic Journal 103: 531-546.

Wei, J. Y. \& Smeers, Y. (1999). Spatial oligopolistic electricity models with Cournot generation and regulated transmission prices, Operations Research 47: 102-112.

Wolak, F. A. \& Patrick, R. (2001). The impact of market rules and market structure on the price determination process in england and wales electricity market, NBER, Working paper 8248.

Wolfram, C. D. (1998). Strategic bidding in a multi-unit auction: an empirical analysis of bids to supply electricity in England and Wales, Rand Journal of Economics 29: 703725 . 
The Center for Economic Studies (CES) is the research division of the Department of Economics of the Katholieke Universiteit Leuven. The CES research department employs some 100 people. The division Energy, Transport \& Environment (ETE) currently consists of about 15 full time researchers. The general aim of ETE is to apply state of the art economic theory to current policy issues at the Flemish, Belgian and European level. An important asset of ETE is its extensive portfolio of numerical partial and general equilibrium models for the assessment of transport, energy and environmental policies.

\section{ETE WORKING PAPER SERIES 2003}

$n^{\circ} 2003-14$

$n^{\circ} 2003-13$

$n^{\circ} 2003-12$

$n^{\circ} 2003-11$

$n^{\circ} 2003-10$

$n^{\circ} 2003-09$

$n^{\circ} 2003-08$

$n^{\circ} 2003-07$

$n^{\circ} 2003-06$

$n^{\circ} 2003-05$

$n^{\circ} 2003-04$

$n^{\circ} 2003-03$

$n^{\circ} 2003-02$

$n^{\circ} 2003-01$
Pepermans G., Willems B. (2003), Regulating transmission in a spatial oligopoly: a numerical illustration for Belgium

Eyckmans J., Pepermans G. (2003), Is er toekomst voor kernenergie in België?

Franckx L. and D'Amato A. (2003), Environmental policy as a multi-task principal-agent problem

Proost S. And Van Dender K. (2003), Marginal Social Cost Pricing For All Transport Modes And The Effects Of Modal Budget Constraints

Mayeres I., Van Regemorter D. (2003), Modelling the health related benefits of environmental policies - a CGE ANALYSIS for the EU countries with GEM-E3

De Borger B., Proost S., Van Dender K. (2003), Congestion And Tax Competition In A Parallel Network

Pepermans G., Driesen J., Haeseldonckx D., D'haeseleer W. and Belmans R. (2003), Distributed generation: definition, benefits and issues

Moons E., The development and application of economic valuation techniques and their use in environmental policy - A survey

Muys B., Deckmyn G., Moons E., Quijano J.G., Proost S. and Ceulemans R. (2003), An integrated decision support tool for the prediction and evaluation of efficiency, environmental impact and total social cost of forestry projects in the framework of the Kyoto protocol

Proost, S. and Van Regemorter, D. (2003), Climate change policy in European countries and its effects on industry

Willems, B. (2003), Should an incumbent generator be allowed to buy import transmission capacity?

Rousseau, S. and Billiet, C.M. (2003), Using emission standards under incomplete compliance

Calthrop, E., De Borger, B. and Proost S. (2003), Tax reform for dirty intermediate goods: theory and an application to the taxation of freight transport

Pepermans, G. (2003), Simulating the restructuring of the Flemish electricity distribution sector 